\title{
CHEMICAL RESISTANCE AND TENSILE PROPERTIES OF BAMBOO AND GLASS FIBERS REINFORCED EPOXY HYBRID COMPOSITES
}

\author{
M. Muthukannan \\ Research Supervisor, Professor of Civil Engineering, \\ Kalasalingam University Krishnankoil, Tamilnadu, India \\ Ance Mathew \\ Research Scholar, Assistant Professor, of Civil Engineering, \\ St. Joseph College of Engineering and Technology, Pala, Kerala, India
}

\begin{abstract}
The chemical resistance of Bamboo/Glass reinforced epoxy hybrid composites to acetic acid, Nitric acid, hydrochloric acid, sodium hydroxide, ammonium hydroxide, sodium carbonate, benzene, toluene, Carbon tetrachloride and water was studied. The Tensile properties of these composites were also studied. The effect of alkali treatment of the bamboo fibers on these properties was studied. It was observed that tensile properties of the hybrid composites increase with glass fiber content. These properties found to be higher when alkali treated bamboo fibers were used in the hybrid composites. The hybrid fiber composites showed better resistance to the chemicals mentioned above. The elimination of amorphous hemi-cellulose with alkali treatment leading to higher crystallinity of the bamboo fibers with alkali treatment may be responsible for these observations.
\end{abstract}

Keywords: Bamboo fiber, Composites, chemical resistance, Epoxy.

Cite this Article: M. Muthukannan and Ance Mathew, Chemical Resistance and Tensile Properties of Bamboo and Glass Fibers Reinforced Epoxy Hybrid Composites. International Journal of Civil Engineering and Technology, 11(3), 2020, pp. 105-108. https://iaeme.com/Home/issue/IJCIET?Volume=11\&Issue=3

\section{INTRODUCTION}

Several studies on the composites made from epoxy matrix and natural fibers like jute, wood, banana, sisal, cotton, coir and wheat straw were reported in the literature. Jindal (1) reported the development of bamboo fiber reinforced plastic composites using araldite (CIBA CY 230) resin as matrix. Though bamboo is extensively used as a valuable material from times immemorial (because of its high strength and low weight), the studies on this fiber reinforced plastics are meager. In the present work, the bamboo \& glass fiber reinforced high performance epoxy hybrid composites were developed and their tensile properties with fiber content (with varying ratio of glass/bamboo fibers) were studied. The effect of alkali 
treatment of the bamboo fibers on these properties was also studied. The chemical resistance properties with varying fiber percentage were also studied.

\section{MATERIAL AND METHODS}

\subsection{Materials}

High performance epoxy resin LY556 and the curing agent hardener HY 951 system were used as the matrix. Bamboo fibers (Dendrocalamus Strictus) were procured from Kerala state of India in the dried form. Some of these fibers were soaked in $1 \% \mathrm{NaOH}$ solution for $30 \mathrm{~min}$. to remove any greasy material and hemi cellulose, washed thoroughly in distilled water and dried under the sun for one week. The fibers with a thickness of $0.3 \mathrm{~mm}$ were selected in the mat form. The glass fibers (chopped form) have been procured
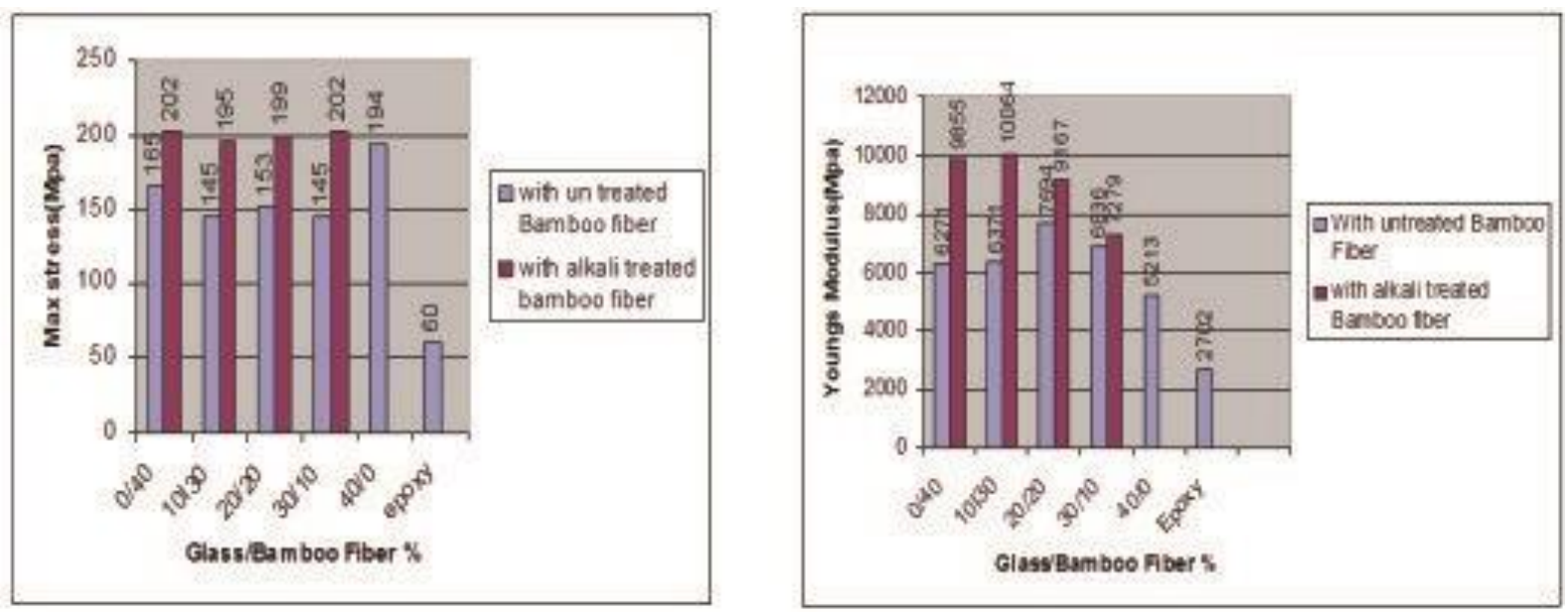

Figure 1 The variation of Tensile Maximum Stress at Yield with ratio of \% Glass/ Bamboo fibers reinforced Epoxy composites from company (Owens Corning fiber glass mat, Bombay) were used in making the hybrid composite percentage

\subsection{Preparation of Mould}

For making the composite, a moulding box was prepared with glass with $200 \mathrm{~mm}$ x $200 \mathrm{~mm}$ x $3 \mathrm{~mm}$ mould cavity.

\subsection{Preparation of the Composite and the Test Specimens}

The mould cavity was coated with a thin layer of aqueous solution of poly vinyl alcohol (PVA) which acts as a good releasing agent. Further a thin coating of hard wax was laid over it and finally another thin layer of PVA was coated. Each coat was allowed to dry for $20 \mathrm{~min}$. at room temperature.

A $3 \mathrm{~mm}$ thick plate was made from the epoxy and hardener taken in the ratio of 100 and 10 parts by weight respectively. Then the moulding box was loaded with the matrix mixture and bamboo \& glass fiber in random orientation (with varying percentage) and was placed in vacuum oven which was maintained at $100{ }^{\circ} \mathrm{C}$ for 3 hours to complete the curing. After curing, the plate was removed from the moulding box with simple tapering and it was cut into samples for tensile test with $150 \mathrm{~mm} \times 15 \mathrm{~mm} \times 3 \mathrm{~mm}$ dimensions and for chemical test with dimensions of $10 \mathrm{mmx} 5 \mathrm{~mm} \times 5 \mathrm{~mm}$. For comparison sake the specimen for matrix material were also prepared in similar lines. 


\subsection{Tensile Load Measurement}

The Tensile stress, and Tensile moduli were determined using Instron 3369 Model UTM. The cross head speed for tensile test was maintained at $10 \mathrm{~mm} / \mathrm{min}$. In each case 5 samples

Fig-2 The variation of tensile modulus with ratio of \% Glass/Bamboo fibers reinforced Epoxy composites were tested and the average values are reported.

\subsection{Chemical Resistance of Composites}

The chemical resistance of the composite was studied as per ASTM D 54387 method. For chemical resistance test, the acids namely concentrated hydrochloric acid (10\%), concentrated nitric acid (40\%) and glacial acetic acid (8\%),the alkalis namely aqueous solutions of sodium hydroxide (10\%),ammonium hydroxide (10\%) and sodium carbonate $(20 \%)$ and the solvents -Benzene, carbon tetra chloride, toluene and water were selected .In each case ,ten pre weighed samples were dipped in the respective chemicals under study for 24 hours, removed and immediately washed thoroughly with distilled water and dried by pressing them on both sides by filter papers. The final weight of the samples and \% weight loss /gain was determined. The resistance test was repeated for ten samples in each case and the average values reported.

\section{RESULTS AND DISCUSSION}

The variation of tensile stress and modulus with percentage glass/bamboo fiber ratio is presented in Fig 1 and Fig 2 respectively. For comparison, these values for the matrix are also presented in the same figures. From both these figures it is evident that the tensile properties are enhanced when the alkali treated bamboo fibers were used in the hybrid composites. This is understandable as the hemi cellulose and lignin contents decrease leading to higher percent of crystalline a-cellulose in bamboo fibers on alkali treatment . The minimum and maximum values of tensile modulus for these composites are found to be 2702 and $10067 \mathrm{MPa}$ respectively. Similarly, the stress values vary in the range of 60 to $202 \mathrm{MPa}$. Similar observation was made by Varada Rajulu et al (2 - 9) and Srinivasulu et al (10) in the case of some bamboo composites and polymer coated bamboo fibers.

Table 1 Resistance of Hybrid (glass/bamboo) composite reinforced epoxy to chemical regents percentage of change in weight after immersion for 24 Hours.

\begin{tabular}{|c|c|c|}
\hline Chemicals & Matrix & Composite \\
\hline $40 \%$ nitric acid & +0.2169 & +0.25491 \\
\hline $10 \%$ Hydrochloric acid & +0.9665 & +0.25491 \\
\hline $8 \%$ Acetic acid & +0.3965 & +2.4299 \\
\hline $10 \%$ sodium hydroxide & -0.4361 & -2.7191 \\
\hline $20 \%$ sodium carbonate & +0.777 & -3.9756 \\
\hline $10 \%$ Ammonium Hydroxide & -0.3973 & -2.9185 \\
\hline Benzene & -1.371 & -1.346 \\
\hline Toluene & -0.691 & -2.360 \\
\hline Carbon tetrachloride & -1.134 & +4.4458 \\
\hline Water & -1.212 & -1.626 \\
\hline
\end{tabular}

The effect of some acids, alkalis and solvents on the matrix and composite under study is presented in Table -1.From this table it is clearly evident that for matrix and composite, the weight gain is observed after immersion. This is understandable as the matrix is cross linked and as a result formation of gel takes place instead of dissolution. Similar observation was made by Varda Rajulu et al 8 in the case of short bamboo fiber reinforced high performance epoxy composites and Padma priya et al 11 in the case of silk fabric reinforced epoxy 
laminates. It is also observed that the effect of sodium carbonate, benzene toluene and carbon tetrachloride is negligible on both the matrix and composite. The chemical resistance of the hybrid composites with treated bamboo fibers is found to be better for the chemicals mentioned.

\section{CONCLUSIONS}

The hybrid composites of bamboo/glass fiber reinforced epoxy were made and their tensile and chemical resistance properties were studied. The effect of alkali treatment of the bamboo fibers on these properties was studied. These hybrid composites were found to exhibit good tensile and chemical resistance properties. The hybrid composites with alkali treated bamboo fibers were found to possess higher Tensile properties. The composites were found to be resistant to some acids, alkalis and solvents. The elimination of amorphous weak hemi cellulose components from the bamboo fibers on alkali treatment may be responsible for this behavior.

\section{REFERENCES}

[1] Jindal, U.C (1986) Development and testing of bamboo fibers reinforced plastic composites journal of composites 20: 19 (1986)

[2] Varada Rajulu, A., Narasimha Chary, K., Rama Chandra Reddy, G. Void content, density, weight reduction and mechanical properties of short bamboo fibers/ stryrenated polyester composites. J. Bamboo \& Ruttan., 2(2): 95 - 102 (2003)

[3] Varada Rajulu, A., Narasimha Chary, K., Rama Chandra Reddy, G., Meng, Y.Z. Void content, density, weight reduction and mechanical properties of short bamboo fibers/ stryrenated polyster composites. J. Reinforced plastics and composites, 23(2):127 - 130. (2004)

[4] Varada Rajulu, A., Babu rao, G., Lakshminarayana Reddy, R. Chemical resistance and tensile properties of Epoxy/Poly carbonate blend coated bamboo fibers. Journal of Reinforced plastics and composites 20(4): 335 - 340. (2001).

[5] Varada Rajulu, A., Ganga Devi, L., Babu rao, G., Lakshminarayana Reddy, R. Chemical resistance and tensile properties of Epoxy/Unsaturated blend coated Bamboo fibers, Journal of Reinforced plastics and composites 22(11): 1029 - 1034. (2003).

[6] Varada Rajulu, A., Allah Baksh, S., Narasimha Chary, K., Rama Chandra Reddy, G.,Chemical Resistance and tensile properties of short Bamboo fiber Reinforced epoxy composites, Journal of Reinforced plastics and composites 17(17): 1507 1511(1998).

[7] Varada Rajulu, A., Narasimha Chary, K., Rama Chandra Reddy, G., Baburao, G., Ganga Devi, L. Thermo gravimetric analysis of dendro calamus strictus bamboo fibers, Journal of Bamboo and Ruttan 1(3): 247-250.(2002).

[8] Varada Rajulu, A., Narasimha Chary, K., Rama Chandra Reddy, G Chemical resistance and tensile properties of styrenated polyester - coated bamboo fibers, Journal of fiber and textile research. 23: 49-51. (1998). 